\title{
CONSTRUCTION OF MINIMAX CONTROL FOR ALMOST CONSERVATIVE CONTROLLED DYNAMIC SYSTEMS WITH THE LIMITED PERTURBATIONS
}

\author{
Iryna Svyatovets \\ Institute of Mathematics of NAS of Ukraine \\ 3 Tereschenkivska str., Kyiv, Ukraine, 301601 \\ sv.irina0702@gmail.com
}

\begin{abstract}
The problem is considered for constructing a minimax control for a linear stationary controlled dynamical almost conservative system (a conservative system with a weakly perturbed coefficient matrix) on which an unknown perturbation with bounded energy acts.

To find the solution of the Riccati equation, an approach is proposed according to which the matrix-solution is represented as a series expansion in a small parameter and the unknown components of this matrix are determined from an infinite system of matrix equations.

A necessary condition for the existence of a solution of the Riccati equation is formulated, as well as theorems on additive operations on definite parametric matrices. A condition is derived for estimating the parameter appearing in the Riccati equation.

An example of a solution of the minimax control problem for a gyroscopic system is given. The system of differential equations, which describes the motion of a rotor rotating at a constant angular velocity, is chosen as the basis.
\end{abstract}

Keywords: minimax control, almost conservative system, Riccati equation, small parameter, non-negative definite matrix.

\section{Introduction}

In solving practical problems of mechanics, gyroscopy and navigation, models of almost conservative systems, in particular controlled ones, are traditionally used, which characteristics can be substantially improved by means of optimal control methods. Using the specificity of the coefficient matrix in the equations of almost conservative systems, namely, the presence of a large non-degenerate skew-symmetric matrix and a small parameter in the perturbation matrix, the process of solving optimal control problems can be greatly simplified.

Let an unknown perturbation $\mathrm{f}(\mathrm{t})$ with bounded energy act on a controlled linear stationary almost conservative system $[1,2]$. The model will look like

$$
\dot{\mathrm{x}}=\left(\mathrm{A}_{0}+\varepsilon \mathrm{A}_{1}\right) \mathrm{x}+\varepsilon \mathrm{Bu}+\varepsilon \Psi \mathrm{f},
$$

where $\mathrm{x}=\left[\mathrm{x}_{1}, \ldots, \mathrm{x}_{2 \mathrm{n}}\right]^{\mathrm{T}}-2 \mathrm{n}-$ dimensional state vector, $\mathrm{u}=\left[\mathrm{u}_{1}, \ldots, \mathrm{u}_{\mathrm{m}}\right]^{\mathrm{T}}-\mathrm{m}-$ dimensional control vector, $\varepsilon$ - small parameter; $\mathrm{A}_{0}, \mathrm{~A}_{1} \in \mathfrak{R}_{2 \mathrm{n} \times 2 \mathrm{n}}$, where $\mathrm{A}_{0}=-\mathrm{A}_{0}^{\mathrm{T}}$ and $\operatorname{det}\left(\mathrm{A}_{0}\right) \neq 0, \mathrm{~B} \in \mathfrak{R}_{2 \mathrm{n} \times \mathrm{m}}-$ the matrix under control, $\Psi \in \mathfrak{R}_{2 \mathrm{n} \times \mathrm{k}}$ - the matrix under perturbation.

The problem of minimax control [3-5] is to find a control $u(t)$ that minimizes the functional

$$
J=\int_{0}^{\infty}\left(x^{T} Q x+u^{T} u-\gamma^{2} f^{T} f\right) d t
$$

and the influence of perturbation $\mathrm{f}(\mathrm{t})$

The required optimal control will find in the form

$$
\mathrm{u}=-\varepsilon \mathrm{B}^{\mathrm{T}} \mathrm{Sx}
$$

and the worst perturbation

$$
\mathrm{f}=\mathrm{K}_{\mathrm{f}} \mathrm{x}, \mathrm{K}_{\mathrm{f}}=\varepsilon \gamma^{-2} \Psi^{\mathrm{T}} \mathrm{S}
$$


Here $\mathrm{S}$ - a positive definite matrix-solution of the matrix Riccati equation of the following form

$$
\mathrm{S}\left(\mathrm{A}_{0}+\varepsilon \mathrm{A}_{1}\right)+\left(\mathrm{A}_{0}+\varepsilon \mathrm{A}_{1}\right)^{\mathrm{T}} \mathrm{S}-\varepsilon^{2} \mathrm{SBB}{ }^{\mathrm{T}} \mathrm{S}+\gamma^{-2} \varepsilon^{2} \mathrm{~S} \Psi \Psi^{\mathrm{T}} \mathrm{S}+\mathrm{Q}=0 .
$$

If suppose

$$
\mathrm{P}=\varepsilon S
$$

the matrix equation (5) can be rewritten as follows

$$
\mathrm{P}\left(\mathrm{A}_{0}+\varepsilon \mathrm{A}_{1}\right)+\left(\mathrm{A}_{0}+\varepsilon \mathrm{A}_{1}\right)^{\mathrm{T}} \mathrm{P}-\varepsilon \mathrm{PBB}^{\mathrm{T}} \mathrm{P}+\gamma^{-2} \varepsilon \mathrm{P} \Psi \Psi^{\mathrm{T}} \mathrm{P}+\varepsilon \mathrm{Q}=0
$$

It is known [3] that there exists a minimal value $\gamma=\gamma_{\min }$ such that for all values $\gamma \in\left[\gamma_{\min }, \infty\right)$ the matrix $\mathrm{P}$ - positive definite, and for $\gamma<\gamma_{\min }$ the matrix $\mathrm{P}$ is alternating.

Thus, in order to find the minimax control, it is required to perform an estimation of the parameter $\gamma$ and to indicate a method for finding the matrix-solution $\mathrm{P}$ of the matrix Riccati equation.

\section{Materials and methods of research}

To find the matrix solution $\mathrm{P}$ of equation (7), the approach proposed for solving the problem of optimal control of almost conservative systems is applied [6-8]. The matrix-solution is represented as a series expansion in powers of a small parameter. As a result of equating the coefficients for the same powers, an infinite system of matrix equations is obtained. A consistent solution of a certain number of equations of this system gives the desired approximation of the solution.

To estimate the parameter $\gamma$ and to fulfill the condition of non-negative definiteness of the matrix included in the Riccati equation, a number of theorems are formulated, the proofs of which are based on the fundamental concepts of matrix theory [9-11]. In particular, the dependencies between the ranks of matrices and the dimensions of their zero spaces are used, as well as the properties of the ranks of matrices under transpose. Some properties of the eigenvalues of the matrix are used, in particular, the property of the continuous dependence of the eigenvalues of the matrix on its elements.

\section{Results of the investigation of the matrix Riccati equation of a special form}

3. 1. A necessary condition for the existence of a solution of equation

Let's write equation (7) in a form convenient for further investigation

$$
\mathrm{P}\left(\mathrm{A}_{0}+\varepsilon \mathrm{A}_{1}\right)+\left(\mathrm{A}_{0}+\varepsilon \mathrm{A}_{1}\right)^{\mathrm{T}} \mathrm{P}-\varepsilon \mathrm{P}\left(\mathrm{BB}^{\mathrm{T}}-\gamma^{-2} \Psi \Psi^{\mathrm{T}}\right) \mathrm{P}+\varepsilon \mathrm{Q}=0 .
$$

Based on the minimax control problem formulation, it is evident that the non-zero elements of the matrix $\Psi$ can be placed only in those rows in which there are non-zero elements of the matrix B. It should be a necessary condition for the existence of solutions of the equation (8), namely,

$$
\operatorname{rang}(\mathrm{B}) \geq \operatorname{rang}(\Psi)
$$

It is known [9] that $\operatorname{rang}\left(\mathrm{AA}^{\mathrm{T}}\right)=\operatorname{rang}(\mathrm{A})$. Then condition (9) can be rewritten in the form

$$
\operatorname{rang}\left(\mathrm{BB}^{\mathrm{T}}\right) \geq \operatorname{rang}\left(\Psi \Psi^{\mathrm{T}}\right)
$$

In this case, the matrix

$$
\mathrm{BB}^{\mathrm{T}}-\gamma^{-2} \Psi \Psi^{\mathrm{T}}
$$

must be non-negative definite. 


\section{2. Additive operations on definite parametric matrices.}

Theorem 1. Let identically defined matrices $A, B \in \mathfrak{R}_{n \times n}, n>\operatorname{rang}(A) \geq \operatorname{rang}(B) \geq 1$ are given.

A matrix $\mathrm{A}-\delta \mathrm{B}, \delta>0$ is identically defined with $\mathrm{A}, \mathrm{B}$ and if and only if the following conditions are satisfied:

$$
\operatorname{rang}(\mathrm{A})=\operatorname{rang}[\mathrm{A}, \mathrm{B}], 0<\delta \leq \delta_{\min },
$$

where $\delta_{\text {min }}$ - the minimum among the positive eigenvalues of matrix pencil $\mathrm{A}-\delta \mathrm{B}$.

Proof. Let's carry out the proof for non-negative definite matrices A, B. In the case of their non-positive definiteness, it can consider a non-negative definite matrix of the form $-(\mathrm{A}-\delta \mathrm{B})$.

Necessity. If the first condition (12) is not satisfied, i. e. $\operatorname{rang}(\mathrm{A})<\operatorname{rang}[\mathrm{A}, \mathrm{B}]$, then the zero-space of the matrix A will be of greater dimension than the zero-space of the matrix [A, B]. And this means that there is a vector $\mathrm{x} \neq 0$ for which the following is true:

$$
\mathrm{x}^{\mathrm{T}}(\mathrm{A}-\delta \mathrm{B}) \mathrm{x}=-\delta \mathrm{x}^{\mathrm{T}} \mathrm{Bx}<0
$$

Thus, it follows from (13) that if the first condition (12) is not satisfied, the matrix $\mathrm{A}-\delta \mathrm{B}$ is not a non-negative definite matrix for an arbitrary $\delta>0$.

Let's suppose that equality $\operatorname{rang}(\mathrm{A})=\operatorname{rang}[\mathrm{A}, \mathrm{B}]$ holds. Then for an arbitrary vector $\mathrm{x}$ of zero-space of the matrix $A$ the following is true: $x^{T} A x=x^{T} B x=0$. Let's consider a matrix pencil $\mu \mathrm{A}-\mathrm{B}$ having, for a parameter $\delta=1 / \mu$, the range of values that is the same as a pencil $\mathrm{A}-\delta \mathrm{B}$. For sufficiently large values $\mu>0$, let's obtain $\mathrm{y}^{\mathrm{T}}(\mu \mathrm{A}-\mathrm{B}) \mathrm{y} \geq 0$ for all vectors. It is known [11] that the eigenvalues of the matrix depend continuously on its elements, so that the eigenvalues of the matrix $\mu \mathrm{A}-\mathrm{B}$ do not pass through zero to the first eigenvalue of the matrix pencil $\mu \mathrm{A}-\mathrm{B}$ on the right of the axis $\mu$. Let's denote this maximum eigenvalue as $\mu_{\max }$. It is positive, otherwise $\mu_{\max } \mathrm{A}-\mathrm{B}$ will be a non-positive matrix, which violates the principle of continuous dependence of eigenvalues on matrix elements.

There is a vector $\mathrm{x} \in \mathfrak{R}_{\mathrm{n}}$ such that $\mathrm{x}^{\mathrm{T}}\left(\mu_{\max } \mathrm{A}-\mathrm{B}\right) \mathrm{x}=0$ and $\mathrm{x}^{\mathrm{T}} \mathrm{Ax} \neq 0 \quad(\operatorname{rang}(\mathrm{A})>$ $\left.>\operatorname{rang}\left[\mu_{\max } \mathrm{A}-\mathrm{B}\right]\right)$ and $\mathrm{x}^{\mathrm{T}} \mathrm{Bx} \neq 0$. Then for $0<\mu<\mu_{\max } \mathrm{x}^{\mathrm{T}}(\mu \mathrm{A}-\mathrm{B}) \mathrm{x}<0$ and the matrix $\mu \mathrm{A}-\mathrm{B}$ is not non-negative definite. Hence $\mathrm{x}^{\mathrm{T}}\left(\mathrm{A}-\frac{1}{\mu} \mathrm{B}\right) \mathrm{x}=\mathrm{x}^{\mathrm{T}}(\mathrm{A}-\delta \mathrm{B}) \mathrm{x}<0$ for $0<\mu=\frac{1}{\delta}<\mu_{\max }$. Consequently, the matrix $\mathrm{A}-\delta \mathrm{B}$ is not non-negative definite if $\delta>\delta_{\min }=1 / \mu_{\max }$.

Sufficiency. If the first condition (12) is satisfied, then, as was shown above, the matrix $\mu \mathrm{A}-\mathrm{B}$ is non-negative definite, when $\mu \geq \mu_{\max }$. Therefore, the matrix $\mathrm{A}-\delta \mathrm{B}$ is non-negative definite if $0<\delta \leq \delta_{\min }$.

Consequence 1. Let's suppose that the identically defined matrices $\mathrm{A}, \mathrm{B} \in \mathfrak{R}_{\mathrm{n} \times \mathrm{n}}$ are given.

A parametric matrix $\mathrm{A}+\delta \mathrm{B}$ can be identically and oppositely defined with respect to matrices $\mathrm{A}, \mathrm{B}$ if and only if the following conditions are satisfied:

$$
\begin{gathered}
\operatorname{rang}(\mathrm{A})=\operatorname{rang}(\mathrm{B})=\operatorname{rang}[\mathrm{A}, \mathrm{B}], \\
\delta_{\text {max }} \leq \delta<+\infty \\
-\infty<\delta \leq \delta_{\text {min }}
\end{gathered}
$$

and condition (15) gives the same definiteness, and condition (16) - the opposite. $\delta_{\min }, \delta_{\max }-$ respectively, the minimum and maximum eigenvalues of the matrix pencil $\mathrm{A}+\delta \mathrm{B}$.

Consequence 2. Let's suppose that matrices $\mathrm{B} \in \mathfrak{R}_{\mathrm{n} \times \mathrm{m}}, \Psi \in \mathfrak{R}_{\mathrm{n} \times 1}, \mathrm{n}>\operatorname{rang}(\mathrm{B})=\mathrm{m} \geq$ $\geq \operatorname{rang}(\Psi) \geq 1$ are given and

$$
\Psi=\mathrm{BH}, \quad \mathrm{H} \in \Re_{\mathrm{m} \times 1} .
$$


A parametric matrix $\mathrm{BB}^{\mathrm{T}}-\frac{1}{\gamma^{2}} \Psi \Psi^{\mathrm{T}}$ is non-negative definite if and only if when the next condition is satisfied

$$
|\gamma| \geq \sqrt{\lambda_{\max }\left(\mathrm{HH}^{\mathrm{T}}\right)}
$$

Consequence 3. Let a convergent series of equally definite matrices $A=A_{1}+A_{2}+\ldots$, $\mathrm{n}>\operatorname{rang}\left(\mathrm{A}_{1}\right) \geq \operatorname{rang}\left(\mathrm{A}_{\mathrm{i}}\right), \mathrm{A}_{\mathrm{i}} \in \mathfrak{R}_{\mathrm{n}_{\mathrm{i}} \times \mathrm{n}_{\mathrm{i}}}, \mathrm{i}=1,2, \ldots$ is given

For a definite matrix $A$, the condition $\operatorname{rang}(A)=\operatorname{rang}\left(A_{1}\right)$ is satisfied if and only if

$$
\operatorname{rang}\left(\mathrm{A}_{1}\right)=\operatorname{rang}\left[\mathrm{A}_{1}, \mathrm{~A}_{\mathrm{i}}\right], \mathrm{i}=2,3, \ldots
$$

In the case of an indefinite symmetric matrix $\mathrm{B}$, one can also give conditions for the determinacy of the matrix $\mathrm{A}+\delta \mathrm{B}$.

Theorem 2. Let a definite matrix $\mathrm{A} \in \mathfrak{R}_{\mathrm{n} \times \mathrm{n}}$ and an indefinite symmetric matrix $\mathrm{B} \in \mathfrak{R}_{\mathrm{n} \times \mathrm{n}}$ are given, for which is satisfied

$$
\begin{gathered}
\mathrm{n}>\operatorname{rang}(\mathrm{A}) \geq \operatorname{rang}(\mathrm{B}) \geq 1, \\
\operatorname{rang}(\mathrm{A})=\operatorname{rang}[\mathrm{A}, \mathrm{B}] .
\end{gathered}
$$

The matrix $\mathrm{A}+\delta \mathrm{B}$ is identically defined with $\mathrm{A}$ and if and only if, when $\delta \in \mathrm{r}_{\delta}$, where

$$
\mathrm{r}_{\delta}=\left[\delta_{\max }^{-}, \delta_{\min }^{+}\right]
$$

and $\delta_{\max }^{-}, \delta_{\min }^{+}$- respectively, the maximum among the negative and the minimum among the positive eigenvalues of the matrix pencil $\mathrm{A}+\delta \mathrm{B}$.

If the matrix $B$ is defined and $\operatorname{rang}(A)>\operatorname{rang}(B) \geq 1$, then there are infinite intervals $\left(-\infty, \delta_{\min }^{+}\right],\left[\delta_{\max }^{-},+\infty\right)$ (it follows from theorems 1 and 2$)$. And the first interval corresponds to a matrix B opposite defined with respect to the matrix A, and the second one to identically defined.

Theorem 3. Let a definite matrix $\mathrm{A} \in \mathfrak{R}_{\mathrm{n} \times \mathrm{n}}$ and an indefinite symmetric matrix $\mathrm{B} \in \mathfrak{R}_{\mathrm{n} \times \mathrm{n}}$, $\mathrm{n}>\operatorname{rang}(\mathrm{A}) \geq 1$, are given, for which inequality is satisfied

$$
\operatorname{rang}(\mathrm{A}) \neq \operatorname{rang}[\mathrm{A}, \mathrm{B}]
$$

The matrix $\mathrm{A}+\delta \mathrm{B}$ is identically defined with a matrix $\mathrm{A}$ if and only if the following conditions are satisfied: for all zero-space vectors $\mathrm{x}$ of the matrix $\mathrm{A}$, non-zero values

$$
\mathrm{J}_{\mathrm{x}}=\left(\mathrm{x}^{\mathrm{T}} \mathrm{Bx}\right) \lambda(\mathrm{A})
$$

has a one sign

$$
\delta \in \begin{cases}{\left[0, \delta_{\min }^{+}\right],} & \mathrm{J}_{\mathrm{x}} \geq 0, \\ {\left[\delta_{\max }^{-}, 0\right],} & \mathrm{J}_{\mathrm{x}} \leq 0,\end{cases}
$$

where $\delta_{\max }^{-}, \delta_{\min }^{+}-$respectively, the maximum among the negative and the minimum among the positive eigenvalues of the matrix pencil $\mathrm{A}+\delta \mathrm{B}$.

For identically and oppositely defined matrices $\mathrm{B}$ with respect to the matrix $\mathrm{A}$, the intervals (25) will be respectively: $[0, \infty)$ and $(-\infty, 0]$. If $\operatorname{rang}(\mathrm{A})=\mathrm{n}$ and $\mathrm{B}$ is an arbitrary undefined symmetric matrix, let's obtain an interval $\left[\delta_{\max }^{-}, \delta_{\min }^{+}\right]$(it follows from theorems 2 and $\left.3 ; \mathrm{J}_{\mathrm{x}}=0\right)$. 
Let's propose one more criterion of identical determinacy of matrices $A$ and $A-\delta B$, less convenient for practice, and based on the theorem of simultaneous (by one non-degenerate transformation) reduction to diagonal form of two definite matrices [12].

Theorem 4. Let's suppose defined matrices $A, B \in \mathfrak{R}_{\mathrm{n} \times \mathrm{n}}, \mathrm{n}>\operatorname{rang}(\mathrm{A}) \geq \operatorname{rang}(\mathrm{B}) \geq 1$ for which equality is satisfied:

$$
\operatorname{rang}(\mathrm{A})=\operatorname{rang}[\mathrm{A}, \mathrm{B}]
$$

Matrix $A-\delta B=T^{T}\left(D_{A}-\delta D_{B}\right) T, D_{A}=\operatorname{diag}\left\{d_{1}^{a}, \ldots, d_{n}^{a}\right\}, D_{B}=\operatorname{diag}\left\{d_{1}^{b}, \ldots, d_{n}^{b}\right\}$ is identically defined with $\mathrm{A}$ if and only if when

$$
\delta=\left\{\begin{array}{lll}
\left(-\infty,-\mathrm{d}_{\mathrm{k}}^{\mathrm{a}} / \mathrm{d}_{\mathrm{k}}^{\mathrm{b}}\right], & \text { if } & \lambda(\mathrm{A}) \lambda(\mathrm{B}) \leq 0, \\
{\left[-\mathrm{d}_{\mathrm{k}}^{\mathrm{a}} / \mathrm{d}_{\mathrm{k}}^{\mathrm{b}},+\infty\right),} & \text { if } & \lambda(\mathrm{A}) \lambda(\mathrm{B}) \geq 0,
\end{array}\right.
$$

where

$$
\mathrm{k}=\arg \min _{\mathrm{i}}\left\{\left|\mathrm{d}_{\mathrm{i}}^{\mathrm{a}} / \mathrm{d}_{\mathrm{i}}^{\mathrm{b}}\right|\right\}, \mathrm{i} \in \overline{\{1, \mathrm{n}\}}, \mathrm{d}_{\mathrm{i}}^{\mathrm{a}} \mathrm{d}_{\mathrm{i}}^{\mathrm{b}} \neq 0
$$

\section{3. Finding a solution of the Riccati equation of a special kind for almost conservative} systems

To solve equation (8), let's apply the approach presented in $[6,7]$, proposed for solving the problem of optimal control of almost conservative systems with a small parameter. Let's find a matrix-solution in the form of an expansion in the small parameter

$$
\mathrm{P}=\mathrm{P}_{0}+\varepsilon \mathrm{P}_{1}+\varepsilon^{2} \mathrm{P}_{2}+\ldots=\sum_{\mathrm{i}=0}^{\infty} \varepsilon^{\mathrm{i}} \mathrm{P}_{\mathrm{i}}
$$

In the same form let's represent the matrix $Q$

$$
\mathrm{Q}=\mathrm{Q}_{0}+\varepsilon \mathrm{Q}_{1}+\varepsilon^{2} \mathrm{Q}_{2}+\ldots=\sum_{\mathrm{i}=0}^{\infty} \varepsilon^{\mathrm{i}} \mathrm{Q}_{\mathrm{i}}
$$

Substituting (29) and (30) in (8), and equating the coefficients for the same powers $\varepsilon$, let's obtain an infinite system of algebraic equations of Riccati type:

$$
\begin{gathered}
\mathrm{A}_{0} \mathrm{P}_{0}-\mathrm{P}_{0} \mathrm{~A}_{0}=0 \\
\mathrm{~A}_{0} \mathrm{P}_{\mathrm{i}}-\mathrm{P}_{\mathrm{i}} \mathrm{A}_{0}=\mathrm{P}_{\mathrm{i}-1} \mathrm{~A}_{1}+\mathrm{A}_{1}^{\mathrm{T}} \mathrm{P}_{\mathrm{i}-1}-\sum_{\mathrm{k}=0}^{\mathrm{i}-1} \mathrm{P}_{\mathrm{k}} \cdot\left(\mathrm{BB}^{\mathrm{T}}-\gamma^{-2} \Psi \Psi^{\mathrm{T}}\right) \cdot \mathrm{P}_{\mathrm{i}-1-\mathrm{k}}+\mathrm{Q}_{\mathrm{i}-1}, \mathrm{i}=1,2, \ldots
\end{gathered}
$$

To find the desired approximation of the matrix solution $\mathrm{P}$, it is necessary to solve successively the corresponding number of equations of the given system.

\section{An example of solving the minimax control problem for a gyroscopic system}

Let's consider a system of differential equations describing the motion of a rotor rotating at a constant angular velocity [13]

$$
\begin{gathered}
\ddot{x}+\alpha \dot{x}+k^{2} x+\alpha \omega y=\varepsilon b_{1} u_{1}+\varepsilon \psi_{1} f_{1}, \\
\ddot{y}+\alpha \dot{y}+k^{2} y-\alpha \omega y=\varepsilon b_{2} u_{2} .
\end{gathered}
$$

After applying the transformation $\mathrm{T}=\operatorname{diag}\{\mathrm{k}, 1, \mathrm{k}, 1\}$ and taking into account the replacement $\mathrm{x}_{1}=\mathrm{x}, \mathrm{x}_{2}=\dot{\mathrm{x}}, \mathrm{x}_{3}=\mathrm{y}, \mathrm{x}_{4}=\dot{\mathrm{y}}$, the model (33) will fully correspond to the form (1) 


$$
\begin{gathered}
{\left[\begin{array}{c}
\dot{\mathrm{x}}_{1} \\
\dot{\mathrm{x}}_{2} \\
\dot{\mathrm{x}}_{3} \\
\dot{\mathrm{x}}_{4}
\end{array}\right]=\left(\left[\begin{array}{cccc}
0 & \mathrm{k} & 0 & 0 \\
-\mathrm{k} & 0 & 0 & 0 \\
0 & 0 & 0 & \mathrm{k} \\
0 & 0 & -\mathrm{k} & 0
\end{array}\right]+\left[\begin{array}{cccc}
0 & 0 & 0 & 0 \\
0 & -\alpha & -\alpha \omega / \mathrm{k} & 0 \\
0 & 0 & 0 & 0 \\
\alpha \omega / \mathrm{k} & 0 & 0 & -\alpha
\end{array}\right]\right)\left[\begin{array}{l}
\mathrm{x}_{1} \\
\mathrm{x}_{2} \\
\mathrm{x}_{3} \\
\mathrm{x}_{4}
\end{array}\right]+} \\
+\varepsilon\left[\begin{array}{cc}
0 & 0 \\
\mathrm{~b}_{1} & 0 \\
0 & 0 \\
0 & \mathrm{~b}_{2}
\end{array}\right] \cdot\left[\begin{array}{l}
\mathrm{u}_{1} \\
\mathrm{u}_{2}
\end{array}\right]+\varepsilon\left[\begin{array}{c}
0 \\
\psi_{1} \\
0 \\
0
\end{array}\right] \cdot\left[\mathrm{f}_{1}\right] .
\end{gathered}
$$

To simplify the further solution, let's set $b_{1}=1, b_{2}=1, \psi_{1}=1$ and $\varepsilon=1 / \mathrm{k}$.

Taking into account condition (18) and taking into account that the matrices $\mathrm{BB}^{\mathrm{T}}$ and $\mathrm{BB}^{\mathrm{T}}-\frac{1}{\gamma^{2}} \Psi \Psi^{\mathrm{T}}$ should have identical ranks, let's obtain: a positive definite matrix $\mathrm{P}$ is the solution of equation (8) will exist when $|\gamma|>1$.

Let's set in (30) $\mathrm{Q}_{0}=\operatorname{diag}\left\{\mathrm{q}_{01}, \mathrm{q}_{02}, \mathrm{q}_{03}, \mathrm{q}_{04}\right\}, \mathrm{Q}_{\mathrm{i}}=0, \mathrm{i}=1,2, \ldots$ and find the matrix $\mathrm{P}$ up to the first order of smallness with respect to $\varepsilon$, i. e., as $\mathrm{P}=\mathrm{P}_{0}+\varepsilon \mathrm{P}_{1}$. Solving equation (31) and equation (32) at $\mathrm{i}=1,2$ there is:

$$
\mathrm{P}=\left[\begin{array}{cccc}
\mathrm{k} \sqrt{\frac{\gamma^{2}\left(\mathrm{q}_{01}+\mathrm{q}_{02}\right)}{\gamma^{2}-1}} & \frac{\mathrm{q}_{01} \mathrm{k}}{2} & 0 & 0 \\
\frac{\mathrm{q}_{01} \mathrm{k}}{2} & \mathrm{k} \sqrt{\frac{\gamma^{2}\left(\mathrm{q}_{01}+\mathrm{q}_{02}\right)}{\gamma^{2}-1}} & 0 & 0 \\
0 & 0 & \mathrm{k} \sqrt{\mathrm{q}_{03}+\mathrm{q}_{04}} & \frac{\mathrm{q}_{03} \mathrm{k}}{2} \\
0 & 0 & \frac{\mathrm{q}_{03} \mathrm{k}}{2} & \mathrm{k} \sqrt{\mathrm{q}_{03}+\mathrm{q}_{04}}
\end{array}\right] .
$$

Taking into account (6), the desired control will have the form

$$
u=\left[\begin{array}{c}
-\frac{q_{01}}{2} x_{1}-\sqrt{\frac{\gamma\left(q_{01}+q_{02}\right)}{\gamma^{2}-1} x_{2}} \\
-\frac{q_{03}}{2} x_{3}-\sqrt{q_{03}+q_{04}} x_{4}
\end{array}\right]
$$

and the worst perturbation

$$
f=\left[\frac{q_{01}}{2 \gamma^{2}} x_{1}+\sqrt{\frac{q_{01}+q_{02}}{\gamma^{2}\left(\gamma^{2}-1\right)}} x_{2}\right] .
$$

\section{Conclusions}

The minimax control problem for almost conservative systems with a small parameter is investigated.

A necessary condition for the existence of a solution of the Riccati equation of a special form is formulated.

Theorems on additive operations on definite matrices are formulated.

A condition is obtained for estimating the parameter appearing in the Riccati equation. 
A possible approach is proposed for finding a solution of the Riccati equation of a special form for almost conservative systems.

An example of the application of the proposed algorithms to the model of a rotor rotating at a constant angular velocity is given.

In the applied plan, the studies presented in this article are effective for the development of gyroscopic and navigation systems that are stable to perturbations.

\section{References}

[1] Novitskiy, V. V. (2008). Control of gyroscopic systems and other analytical mechanics problems. Pratsi Institutu matematyki NAN Ukrainy. Vol. 78: Matematika ta yiyi zastosuvannya. Kyiv, 124.

[2] Novitskiy, V. V. (2004). Lyapunov equation for almost conservative systems. Kyiv: Institut matematyki NAN Ukrainy, 34 .

[3] Aleksandrov, A. G. (2008). Metody postroeniya system avtomaticheskogo upravleniya [Methods of construction of automatic control systems]. Moscow: Fizmatkniga, 232.

[4] Biryukov, R. S. (2013). Minimax control of linear object in the external disturbance and undefined initial conditions on a finite time interval. Vestnik Nizhegorodskogo universiteta im. N. I. Lobachevskogo. Seriia: Matematicheskoe modelirovanie i optimal'noe upravlenie, 3 (1), 206-211.

[5] Ignashchenko, E. Y., Pankov, A. R., Semenikhin, K. V. (2010). A statistical minimax approach to optimizing linear models under a priori uncertainty conditions. Journal of Computer and Systems Sciences International, 49 (5), 710-718. doi: 10.1134/s1064230710050059

[6] Novitskiy, V. V., Khuan Chen (2004). Optimal control almost conservative systems. Suchasni problemy analitychnoyi mekhaniky, 1 (2), 152-157.

[7] Zinchuk, M. O., Novitskiy, V. V. (2006). Optimal control of continuous almost conservative systems. Problemy analitychnoyi mekhaniky, 3 (1), 75-89.

[8] Zinchuk, M. O., Novitskiy, V. V. (2010). Optimal control of linear parametric system. Zbirnyk prats Institutu matematyki NAN Ukrainy, 7 (3), 171-185.

[9] Horn, R. A., Johnson, C. R. (2012). Matrix Analysis. Ed. 2. Cambridge University Press, 662. doi: $10.1017 /$ cbo9781139020411

[10] Lancaster, P., Tismenetsky, M. (1985). The Theory of Matrices. Academic Press, 570.

[11] Weiss, G. (1960). The Theory of Matrices. vol. 1 and vol. 2. F. R. Gantmacher. Chelsea Publishing Company, New York 68, 1959. vol. 1: $x+374$ pp. vol. 2: $x+277$ pp. \$6 each. Science, 131 (3408), 1216-1216. doi: 10.1126/science.131.3408.1216-a

[12] Prasolov, V. V. (1996). Zadachi i teoremy lineynoy algebry [Problems and theorems of linear algebra]. Moscow: Nauka, 304.

[13] Merkin, D. R. (1996). Introduction to the Theory of Stability. Texts in Applied Mathematics. New York: Springer, 340. doi: 10.1007/978-1-4612-4046-4 